\title{
EDITORIAL
}

\section{Novel therapeutic perspectives in pulmonary arterial hypertension}

\author{
M. Humbert, O. Sitbon, G. Simonneau
}

Pulmonary arterial hypertension (PAH) refers to a disease spectrum of the small pulmonary arteries leading to a progressive increase in pulmonary vascular resistance, right ventricular failure and, ultimately, death [1]. It is usually accepted that a vasoconstrictive factor is involved in PAH [2]. However, pure vasodilators, such as calcium channel blockers, have so far provided little or no beneficial effects on survival in the vast majority of patients, presumably because the pulmonary arteriopathy characteristic of PAH includes fibrotic and proliferative changes that predominate over vasoconstriction [3, 4]. Interestingly, novel therapeutic agents, such as prostacyclin and endothelin-receptor antagonists, have a better clinical efficacy than pure vasodilators in PAH, presumably because they have both vasodilator and antiproliferative properties [4-6].

Prostaglandin I2 (prostacyclin, epoprostenol) has been the most widely studied drug in PAH [5, 7-9]. Epoprostenol has a short half-life in the blood ( $3 \mathrm{~min}$ ) and is inactivated at low $\mathrm{pH}$ [9]. Therefore, epoprostenol can only be administered by continuous intravenous infusion with the use of a portable infusion pump connected to a permanent tunneled catheter inserted into a subclavian vein [5]. Catheter-related sideeffects, such as sepsis and thrombosis, can be severe in this patient population [7]. During initial hospitalisation, patients have to be trained in pump programming, drug preparation, sterile technique and catheter care. Despite favourable outcomes, it is clear that continuous intravenous epoprostenol infusion is a far from ideal treatment for severe PAH because it is complicated, uncomfortable for patients and its financial cost is exceedingly high, especially in Europe.

Other treatments are now approved for PAH. They include subcutaneous prostacyclin analogues (treprostinil) [10] in North America and oral bosentan [6], a dual endothelinreceptor antagonist, in Europe and North America. In May 2003, oral beraprost [11] and inhaled iloprost [12] were under evaluation by European regulatory agencies, while randomised trials evaluated selective endothelin-receptor type-A antagonists (ambrisentan and sitaxsentan) [13] and phosphodiesteraseinhibitor type-5 (sildenafil) [14].

Cohorts of patients receiving chronic intravenous epoprostenol infusion have recently been reported in Europe and North America [7, 8]. Analysis of these cohorts showed that survival depends on the pretherapeutic severity and, most importantly, the 3-month response to therapy. At 3 months, patients in New York Heart Association (NYHA) functional class I or II with a 6-min walk distance of $>380 \mathrm{~m}$ and a fall in total pulmonary resistance of $>30 \%$ relative to baseline, have significant survival benefits [7, 8]. In contrast, the long-term effects of prostacyclin analogues and endothelin-receptor

Dept of Respiratory and Intensive Care Medicine, Centre for Pulmonary Vascular Diseases, Antoine Béclère Hospital, South Paris University, Assistance Publique, Hôpitaux de Paris, Clamart, France.

Correspondence: M. Humbert, Service de Pneumologie, Hôpital Antoine-Béclère, 157, Rue de la Porte de Trivaux, 92140 Clamart, France. Fax: 33 146303824. E-mail: humbert@ipsc.u-psud.fr antagonists are still unknown [15]. There is therefore a substantial need for long-term observational studies evaluating the different treatments in terms of survival, side-effects, quality of life and costs. As head-to-head comparisons of currently approved therapies are not available, the choice of initial treatment will depend on local experiences and administrative regulations, as well as on the clinical context and patient's preference. Most experts recommend that severe NYHA functional class IV patients in an unstable condition should receive continuous intravenous epoprostenol. Aside from this dramatic situation, first-line therapy in NYHA functional class III patients may include endothelin-receptor antagonists or less invasive prostacyclin analogues on careful observation in a pulmonary vascular centre. The best strategy in patients with unsatisfactory results of prostacyclin analogues or endothelin-receptor antagonists is currently unknown and requires additional studies. Adjunct combination therapy [16, 17], transition to intravenous prostacyclin, atrioseptostomy [18] or lung transplantation [19] should be considered in this patient population.

A combination of drugs with distinct mechanisms of action may have additive or synergistic effects in severe PAH. Acute haemodynamical effects of combined therapies have been reported [20-22]. Oral phosphodiesterase type-5 inhibitor sildenafil increases and prolongs the vasodilatory action of inhaled nitric oxide and aerosolised iloprost [20, 21]. In addition, subthreshold dual-selective phosphodiesterase types-3 and -4 inhibition amplifies the lung vasodilatory response to inhaled iloprost [22]. These promising acute effects have supported the development of chronic combination therapy. In this issue of the European Respiratory Journal, HoEPER et al. [16] report interesting findings with adjunct combined therapy in patients with unsatisfactory results of nonparenteral prostacyclin analogues (inhaled iloprost or oral beraprost). This open study supports the concept that combination therapy may offer clinical advantages in this patient population. Similar results have been reported by GHOFRANI et al. [17] with sildenafil in patients receiving nebulised iloprost. Although promising, these open studies need to be confirmed by results from randomised trials. Recently, a single, double-blind placebocontrolled pilot study has evaluated the efficacy and safety of a 16-week combination of bosentan plus intravenous epoprostenol in patients with severe PAH in NYHA functional class III or IV [23]. This combination was well tolerated with a trend for a greater reduction in total pulmonary resistance, as compared to placebo plus epoprostenol [23].

Whether initial or adjunct combined therapy provides additional clinical benefits to patients with severe pulmonary arterial hypertension warrants further investigation.

\section{References}

1. Rubin LJ. Primary pulmonary hypertension. $N$ Engl $J$ Med 1997; 336: 111-117.

2. Palevsky HI, Schloo BL, Pietra GG, et al. Primary 
pulmonary hypertension. Vascular structure, morphometry and responsiveness to vasodilators agents. Circulation 1989; 80: $1207-1221$.

3. Sitbon $\mathrm{O}$, Humbert M, Jagot JL, et al. Inhaled nitric oxide as a screening agent for safely identifying responders to oral calcium-channel blockers in primary pulmonary hypertension. Eur Respir J 1998; 12: 265-270.

4. Rubin LJ. Therapy of pulmonary hypertension: the evolution from vasodilators to antiproliferative agents. $\mathrm{Am} \mathrm{J}$ Respir Crit Care Med 2002; 166: 1309-1310.

5. Barst RJ, Rubin LJ, Long WA, et al. A comparison of continuous intravenous epoprostenol (prostacyclin) with conventional therapy for primary pulmonary hypertension. N Engl J Med 1996; 334: 296-302.

6. Rubin LJ, Badesch DB, Barst RJ, et al. Bosentan therapy for pulmonary arterial hypertension. $N$ Engl J Med 2002; 346: 896-903.

7. Sitbon O, Humbert $\mathrm{M}$, Nunes $\mathrm{H}$, et al. Long-term intravenous epoprostenol infusion in primary pulmonary hypertension: prognostic factors and survival. $\mathrm{J} \mathrm{Am}$ Coll Cardiol 2002; 40: 780-788.

8. McLaughlin VV, Shillington A, Rich S. Survival in primary pulmonary hypertension: the impact of epoprostenol therapy. Circulation 2002; 106: 1477-1482.

9. Galiè N, Manes A, Branzi A. The new clinical trials on pharmacological treatment in pulmonary arterial hypertension. Eur Respir J 2002; 20: 1037-1049.

10. Simonneau G, Barst RJ, Galiè N, et al. Continuous subcutaneous infusion of treprostinil, a prostacyclin analogue, in patients with pulmonary arterial hypertension: a doubleblind randomized controlled trial. Am J Respir Crit Care Med 2002; 165: 800-804.

11. Galiè N, Humbert M, Vachiéry JL, et al. Effects of beraprost sodium, an oral prostacyclin analogue, in patients with pulmonary arterial hypertension: a randomized, doubleblind placebo-controlled trial. J Am Coll Cardiol 2002; 39: 1496-1502.

12. Olschewski H, Simonneau G, Galiè N, et al. Inhaled iloprost in severe pulmonary hypertension. N Engl J Med 2002; 347: 322-327.

13. Barst RJ, Rich SA, Horn EM, McLaughlin VV, McFarlin J.
Clinical efficacy of sitaxsentan, an endothelin-A receptor antagonist, in patients with pulmonary arterial hypertension. Chest 2002; 121: 1860-1868.

14. Prasad S, Wilkinson J, Gatzoulis MA. Sildenafil in primary pulmonary hypertension. N Engl J Med 2000; 343: 1342.

15. Sitbon O, Badesch DB, Cjannick RN, et al. Effect of the dual endothelin receptor antagonist bosentan in patients with pulmonary arterial hypertension: a one year follow-up study. Chest 2003; (in press).

16. Hoeper MM, Taha N, Bekjarova A, Gatzke R, Spiekerkoetter E. Bosentan treatment in patients with primary pulmonary hypertension receiving nonparenteral prostanoids. Eur Respir $J$ 2003; 22: 330-334.

17. Ghofrani A, Rose F, Schermuly RT, et al. Oral sildenafil as long-term adjunct therapy to inhaled iloprost in severe pulmonary arterial hypertension. J Am Coll Cardiol 2003; (in press).

18. Sandoval J, Gaspar J, Pulido T, et al. Graded balloon dilation atrial septostomy in severe primary pulmonary hypertension: a therapeutic alternative for patients nonresponsive to vasodilator treatment. J Am Coll Cardiol 1998; 32: $297-304$

19. Mendeloff EN, Meyers BF, Sundt TM, et al. Lung transplantation for pulmonary vascular disease. Ann Thorac Surg 2002; 73: 209-219.

20. Bigatello LM, Hess D, Dennehy KC, Medoff BD, Hurford WE. Sildenafil can increase the response to inhaled nitric oxide. Anesthesiology 2000; 92: 1827-1829.

21. Ghofrani HA, Wiedemann R, Rose F, et al. Combination therapy with oral sildenafil and inhaled iloprost for severe pulmonary hypertension. Ann Intern Med 2002; 136: 515522.

22. Ghofrani HA, Rose F, Schermuly RT, et al. Amplification of the pulmonary vasodilatory response to inhaled iloprost by subtreshold phosphodiesterases types 3 and 4 inhibition in severe pulmonary hypertension. Crit Care Med 2002; 30: 2489-2492.

23. Humbert M, Barst RJ, Robbins I, et al. Safety and efficacy of bosentan in combination with epoprostenol in patients with severe pulmonary arterial hypertension (abstract). Am J Respir Crit Care Med 2003; 167: A441. 